\title{
Karakterisasi Pasir Besi Alam Pantai Samudera Baru dan Pemanfaatannya sebagai Filler pada Sistem Penyaring Elektromagnetik
}

\section{Characterization of Natural Iron Sand from Samudera Baru Beach and Its Utilization as Filler on Electromagnetic Filtering System}

\author{
Eri Widianto ${ }^{*}$, Kardiman ${ }^{2}$, Najmudin Fauji ${ }^{3}$ \\ 1,2,3)Program Studi Teknik Mesin, Fakultas Teknik Universitas Singaperbangsa Karawang, \\ Jalan H.S. Ronggowaluyo, Telukjambe Timur, Karawang, Indonesia 41361 \\ *email: eri.widi46@gmail.com
}

\begin{abstract}
Histori Artikel:
ABSTRAK

Submitted: $29 / 01 / 2018$

Accepted: $14 / 04 / 2018$

Published: $02 / 06 / 2018$

Telah dilakukan karakterisasi pasir besi alam Pantai Samudera Baru Karawang dan aplikasinya sebagai filler pada penyaring elektromagnetik. Sampel pasir pantai diekstraksi menggunakan magnet permanen untuk memisahkan material magnetik dan non magnetik. Karakterisasi pasir besi menggunakan Scanning Electron Microscopy with Energy Dispersive X-ray (SEM-EDX). Hasil karakterisasi menggunakan SEM-EDX menunjukkan bahwa sampel pasir besi mengandung unsur Fe dan 0 , yang berasal dari fase Magnetit $\left(\mathrm{Fe}_{3} \mathrm{O}_{4}\right)$, Maghemite $\left(\gamma-\mathrm{Fe}_{2} \mathrm{O}_{3}\right)$ dan hematit $\left(\alpha-\mathrm{Fe}_{2} \mathrm{O}_{3}\right)$. Sistem penyaring elektromagnetik dibuat dari pipa PVC berdiameter 1 inchi yang diberi lilitan kawat tembaga berdiameter 0,35 $\mathrm{mm}$, panjang kolom penyaring $50 \mathrm{~cm}$ dengan 1050 lilitan dan dimasukkan pasir besi 500 gram sebagai media penyaring. Penyaringan dilakukan dengan mengalirkan sampel air dengan besar arus konstan yaitu 2 A. Hasil pengujian menggunakan Spektroskopi Serapan Atom (SSA) menunjukkan penurunan kadar logam Fe dari 1,228 ppm menjadi 0,0510 ppm dan $0,0813 \mathrm{ppm}$.
\end{abstract}

Kata Kunci : pasir besi, SEM-EDX, sistem penyaring elektromagnetik

\begin{abstract}
Characterization of natural iron sand from Samudera Baru beach - Karawang and its application as filler on electromagnetic filtering system has been done. Iron sand samples was extracted using permanent magnets to separate magnetic and non-magnetic materials. Characterization of iron sand using Scanning Electron Microscopy with Energy Dispersive X-ray (SEM-EDX). The result of SEM-EDX shows that iron sand samples contains Fe and $\mathrm{O}$ elements, derived from Magnetite $\left(\mathrm{Fe}_{3} \mathrm{O}_{4}\right)$, Maghemite $\left(\gamma-\mathrm{Fe}_{2} \mathrm{O}_{3}\right)$ and Hematite $\left(\alpha-\mathrm{Fe}_{2} \mathrm{O}_{3}\right)$. Electromagnetic filtering system is made of PVC pipe with 1 inch of diameter, that has been coiled by 0.35 $\mathrm{mm}$ of diameter wire, column length filtering at $50 \mathrm{~cm}$ with 1050 coils and filled with 500 grams iron sand as filter media. Filtering is done by to flow the water well in the electromagnetic filtering system with constant current 2 A. The result of Atomic Absorption Spectroscopy (AAS) shows reduce levels of Fe metal with high levels of early $1.228 \mathrm{ppm}$ to $0.0510 \mathrm{ppm}$ and $0.0813 \mathrm{ppm}$.
\end{abstract}

Key words: iron sand, SEM-EDX, electromagnetic filtering system

\section{PENDAHULUAN}

Penelitian tentang pengolahan dan karakterisasi pasir besi di Indonesia telah banyak dilakukan. Namun, penelitian tersebut masih terus dikembangkan guna memanfaatkan deposit pasir besi yang melimpah. Keberadaan pasir besi yang terdistribusi luas dan jumlahnya melimpah memberikan daya tarik secara ekonomi untuk dikembangkan menjadi produk yang berdaya guna lebih (Musthofa et al., 2016; Yulianto, Aji, \& Idayanti, 2010). Kabupaten Karawang berada di bagian utara Propinsi Jawa Barat berbatasan 
langsung dengan Laut Jawa. Sebagian besar wilayah Kabupaten Karawang tertutup dataran pantai luas yang terhampar di bagian pantai utara dengan panjang pantai 73,65 km (SLH Karawang, 2013). Sehingga sangat berpotensi untuk pengolahan pasir besi.

Kandungan besi (Fe) dalam pasir besi banyak dimanfaatkan sebagai bahan baku pembuatan baja. Selain itu, pasir besi juga mengandung mineral magnetik seperti magnetit $\left(\mathrm{Fe}_{3} \mathrm{O}_{4}\right)$, hematit $\left(\alpha-\mathrm{Fe}_{2} \mathrm{O}_{3}\right)$ dan maghemit $(\gamma$ $\mathrm{Fe}_{2} \mathrm{O}_{3}$ ) yang dapat diaplikasikan diberbagai bidang (Husain, Suarso, \& Maddu, 2016; Rahwanto, 2013; Yulianto et al., 2010). Salah satu bahan kajian yang menarik beberapa tahun terakhir adalah nanopartikel, yaitu material berukuran lebih kecil dari $100 \mathrm{~nm}$. Nanopartikel memiliki sifat fisik, kimia, mekanik, magnetik dan optik yang unik yang tidak dimiliki oleh material lain. Nanopartikel dapat dimanfaatkan untuk berbagai aplikasi, seperti biosensor, perangkat fotonik dan medik (Yulianto et al., 2010).

Nanopartikel magnetik merupakan salah satu material yang banyak diteliti belakangan ini. Kandungan magnetit $\left(\mathrm{Fe}_{3} \mathrm{O}_{4}\right)$ pada pasir pantai dapat diolah menjadi nanopartikel magnetit $\left(\mathrm{Fe}_{3} \mathrm{O}_{4}\right)$ maupun bahan dasar magnet permanen.

Penelitian menunjukan bahwa magnetit $\left(\mathrm{Fe}_{3} \mathrm{O}_{4}\right)$ dapat diaplikasikan sebagai magnetic recording media, high density digital recording disk, magnetic fluids, data storage, MRI, drug delivery system, biosensor SPR, microwave device dan magnetic sensing (Ghandoor, Zidan, Khalil, \& Ismail, 2012). Nanopartikel magnetit $\left(\mathrm{Fe}_{3} \mathrm{O}_{4}\right)$ dapat diperoleh dari bahan sintesis dan bahan alam. Pertimbangan penggunaan bahan alam dari pasir besi (iron sands) atau pasir hitam (black sands) yaitu karena melimpahnya sumber bahan alam yang ada dan belum termanfaatkan serta biaya pembuatannya lebih murah. Eksplorasi pasir besi sebagai nanopartikel masih terbatas dibandingkan jumlah dan eksplorasi pasir besi untuk bahan mentah. Hal ini yang menjadikan tantangan kajian penelitian dibidang nanomaterial (Fuad, Wulansari, \& Taufiq, 2010).

Guna menggali potensi pasir besi Pantai Samudera Baru perlu dilakukan analisis kandungan mineral magnetiknya. Penelitian ini akan dilakukan karakterisasi dan analisis kandungan unsur pada pasir besi menggunakan SEM-EDX, yang selanjutnya digunakan sebagai filler pada sistem penyaring elektromagnetik. Sistem Penyaring Elektromagnetik (SPE) bekerja berdasarkan prinsip medan magnet yang ditimbulkan oleh adanya arus listrik yang dialirkan pada sebuah solenoid. Medan magnet ini digunakan sebagai penyaring dalam SPE. Sistem ini juga menggunakan media penyaring berupa pasir besi yang merupakan bahan mudah termagnetisasi dan jumlahnya melimpah di alam. Beberapa jenis logam berat dalam limbah cair yang pernah disaring dengan SPE antara lain logam Besi (Fe) dan Mangan (Mn) dengan kadar logam setelah penyaringan sebesar 0,466 ppm dan 0,440 ppm (Zain \& Muliawan, 2016).

Pada SPE terdapat beberapa faktor yang mempengaruhi tingkat efektivitas dalam menurunkan kadar logam pada sampel, diantaranya kuat arus, kadar awal logam, pasir besi, diameter lilitan, jumlah lilitan, panjang kolom penyaring dan arah medan magnet. Pasir besi yang digunakan pada sistem penyaring elektromagnetik merupakan salah satu bahan ferromagnetic, sehingga dapat memberikan gaya magnet pada benda yang berada di sekitarnya termasuk menarik logam berat yang terlarut pada limbah cair yang melaluinya sekaligus mengurangi warna dan bau dari air yang tercemar.

\section{METODE PENELITIAN}

\section{A. Persiapan Bahan dan Peralatan}

Bahan penelitian yang digunakan pada penelitian ini meliputi: Sampel pasir dari Pantai Samudera Baru Karawang, Sampel air sungai di Karawang, larutan $\mathrm{HCl}$ dan aquades. Sedangkan peralatan penelitian yang digunakan meliputi: Saringan, beker gelas, gelas ukur, pipet, timbangan digital, spatula, magnet permanen, mortar, cawan, hot plate stirrer, pipa PVC dan penyambung pipa, regulator, wadah penampung, kran, rangkaian penyearah, multimeter, teslameter, kawat tembaga, busa penyaring, $\mathrm{pH}$ indikator dan kertas saring.

\section{B. Proses Ekstraksi Pasir Besi}

Langkah awal yang dilakukan yaitu mengekstraksi pasir besi alam. Sampel pasir disaring menggunakan ayakan untuk memisahkan pasir dengan kotoran dan komponen-komponen kasar lainnya. Selanjutnya, memisahkan material magnetik dan non magnetiknya dengan menggunakan magnet permanen. Sampel magnetik dicuci menggunakan aquades, kemudian dikeringkan. Untuk mendapatkan sampel yang lebih halus maka dilakukan penghalusan sampel menggunakan cawan dan mortar. Selanjutnya sampel dicuci kembali dan dikeringkan pada suhu sekitar $100{ }^{\circ} \mathrm{C}$. Karakterisasi sampel pasir besi menggunakan SEM-EDX untuk mengetahui struktur morfologi dan kandungan unsur yang terdapat pada pasir besi. 


\section{Eri Widianto, Kardiman, Najmudin Fauji}

Karakterisasi Pasir Besi Alam Pantai Samudera Baru dan Pemanfaatannya sebagai Filler pada Sistem Penyaring Elektromagnetik

\section{Sistem penyaring elektromagnetik}

Rangkaian sistem penyaring dibuat dari pipa PVC berdiameter 1 inci sepanjang $65 \mathrm{~cm}$ yang dililiti kawat tembaga berdiameter $\pm 0,35$ $\mathrm{mm}$, panjang lilitan $50 \mathrm{~cm}$ dan terdiri dari \pm 1050 lilitan. Selanjutnya dirangkai dengan peralatan pendukung seperti regulator, multimeter digital dan rangkaian penyearah.

\section{HASIL DAN PEMBAHASAN}

Pasir besi yang diekstrak dari pasir alam Pantai Samudera Baru memiliki karakteristik berwarna hitam dan mengandung sekitar 25\% material magnetik dan $75 \%$ material non magnetik. Sampel pasir besi dapat dilihat pada Gambar 1 berikut:
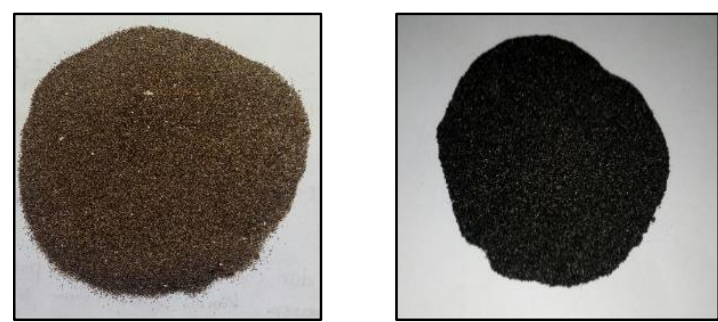

Gambar 1. Pasir besi sebelum diproses (kiri) dan sesudah diproses (kanan)

Gambar 1 menunjukan perbedaan antara pasir pantai sebelum dan sesudah diekstraksi. Perubahan warna terlihat jelas untuk pasir besi berwarna hitam yang menunjukan banyak kandungan besi oksida. Sifat juga kemagnetan meningkat dibuktikan dengan semakin kuat sampel ditarik dengan magnet permanen.

Struktur morfologi sampel pasir besi menggunakan SEM-EDX ditunjukkan pada Gambar 2

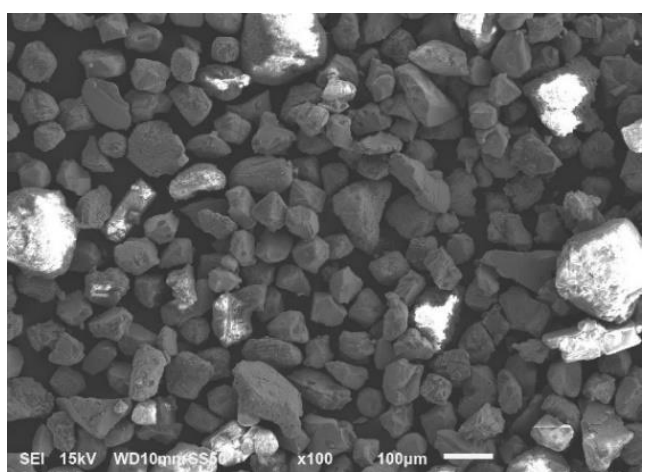

Gambar 2. Struktur morfologi sampel pasir besi menggunakan SEM

Gambar 2 terlihat bahwa ukuran butir sampel pasir besi tidak seragam. Namun sudah dapat diperoleh sampel dengan ukuran diameter yang kecil. Dengan menggunakan software
Image-J diperoleh estimasi ukuran diameter sampel pasir besi rata-rata $\pm 78 \mu \mathrm{m}$, dapat dilihat pada Gambar 3 berikut:

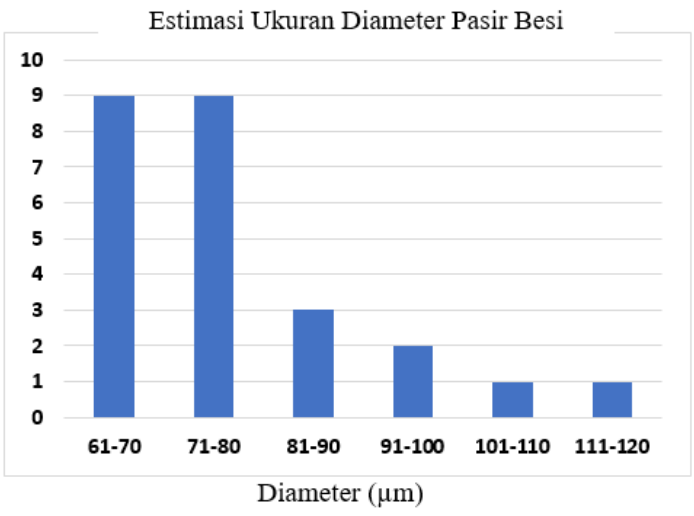

Gambar 3. Distribusi ukuran diameter sampel pasir besi

Selanjutnya dilakukan analisis kandungan sampel pasir besi menggunakan EDX untuk beberapa titik pengukuran.

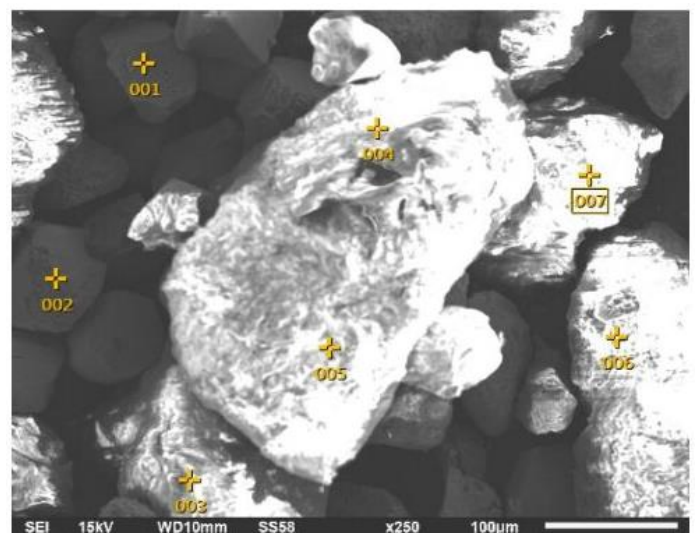

Gambar 4. Struktur morfologi sampel pasir besi menggunakan SEM-EDX

Karakterisasi menggunakan EDX diperoleh informasi kandungan unsur yang terdapat pada pasir besi. Hasil karakterisasi sampel pasir besi untuk titik 001 dapat dilihat pada Gambar 5 dan Tabel 1 berikut.

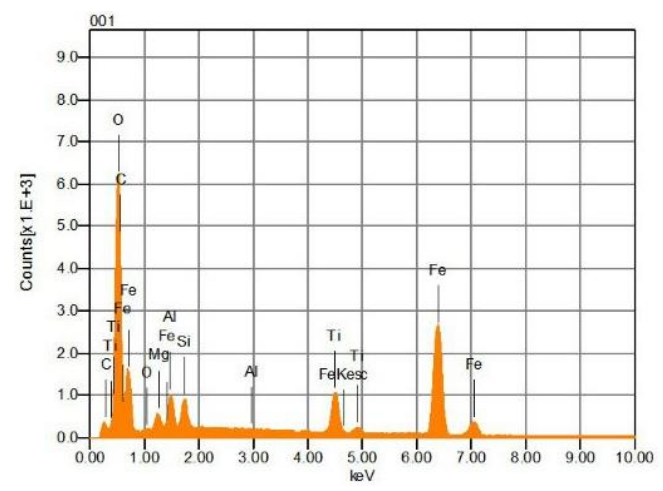

Gambar 5. Spektrum karakterisasi pasir besi menggunakan EDX 


\section{Eri Widianto, Kardiman, Najmudin Fauji}

Karakterisasi Pasir Besi Alam Pantai Samudera Baru dan Pemanfaatannya sebagai Filler pada Sistem Penyaring Elektromagnetik

Tabel 1. Kandungan unsur pada sampel pasir besi (titik 001)

\begin{tabular}{lll}
\hline Formula & mass\% & Atom\% \\
\hline $\mathrm{C}$ & 3.48 & 8.53 \\
$\mathrm{O}$ & 27.14 & 49.88 \\
$\mathrm{Mg}$ & 2.53 & 3.05 \\
$\mathrm{Al}$ & 3.27 & 3.57 \\
$\mathrm{Si}$ & 1.55 & 1.63 \\
$\mathrm{Ti}$ & 7.65 & 4.70 \\
$\mathrm{Fe}$ & 54.38 & 28.64 \\
$\mathrm{Total}$ & 100 & 100 \\
\hline
\end{tabular}

Hasil karakterisasi sampel pasir besi untuk titik 002 dapat dilihat pada Gambar 6 dan Tabel 2 berikut.

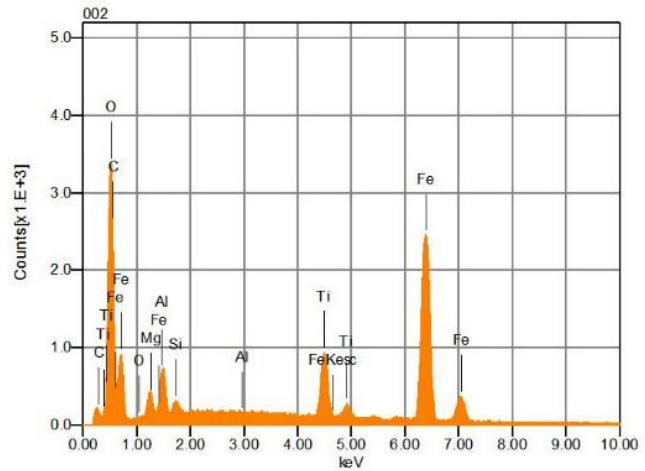

Gambar 6. Spektrum karakterisasi pasir besi menggunakan EDX

Tabel 2. Kandungan unsur pada sampel pasir besi (titik 002)

\begin{tabular}{lll}
\hline Formula & mass\% & Atom\% \\
\hline $\mathrm{C}$ & 2.71 & 7.61 \\
$\mathrm{O}$ & 18.54 & 39.17 \\
$\mathrm{Mg}$ & 2.96 & 4.12 \\
$\mathrm{Al}$ & 3.21 & 4.02 \\
$\mathrm{Si}$ & 0.48 & 0.58 \\
$\mathrm{Ti}$ & 8.49 & 5.99 \\
$\mathrm{Fe}$ & 63.61 & 38.50 \\
Total & 100 & 100 \\
\hline
\end{tabular}

Hasil karakterisasi sampel pasir besi untuk titik 003 dilihat pada Gambar 7 dan Tabel 3.

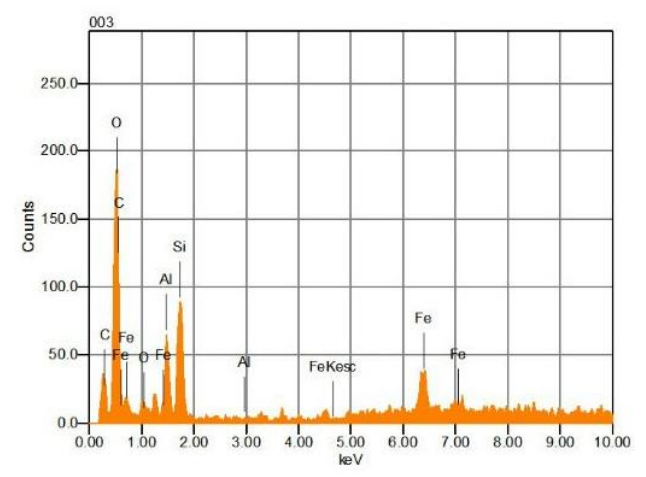

Gambar 7. Spektrum karakterisasi pasir besi menggunakan EDX

Tabel 3. Kandungan unsur pada sampel pasir besi (titik 003)

\begin{tabular}{lll}
\hline Formula & mass\% & Atom\% \\
\hline $\mathrm{C}$ & 18.13 & 30.38 \\
$\mathrm{O}$ & 37.80 & 47.54 \\
$\mathrm{Al}$ & 8.40 & 6.27 \\
$\mathrm{Si}$ & 8.32 & 5.96 \\
$\mathrm{Fe}$ & 27.34 & 9.85 \\
Total & 100 & 100 \\
\hline
\end{tabular}

Karakterisasi pasir besi menggunakan SEM-EDX menunjukan bahwa sampel pasir besi yang diekstrak dari pasir alam Pantai Samudera Baru Karawang banyak mengandung unsur Fe dan O. Pada titik 001 kandungan unsur Fe dan 0 masing-masing 54,38\% dan 27,14\%. Pada titik 002 kandungan unsur Fe dan 0 masing-masing 43,61\% dan 18,54 \%. Sedangkan pada titik 003 kandungan unsur $\mathrm{Fe}$ dan $\mathrm{O}$ masing-masing 27,34\% dan 37,80\%. Kandungan Fe dan $\mathrm{O}$ berasal dari fase Magnetit $\left(\mathrm{Fe}_{3} \mathrm{O}_{4}\right)$, maghemit $\left(\gamma-\mathrm{Fe}_{2} \mathrm{O}_{3}\right)$, dan hematit $\left(\alpha-\mathrm{Fe}_{2} \mathrm{O}_{3}\right)$ yang merupakan besi oksida yang telah umum ditemukan pada pasir besi (Kartika \& Pratapa, 2014; Septityana et al., 2013). Sedangkan beberapa unsur lain seperti K, $\mathrm{C}, \mathrm{Na}, \mathrm{Mg}, \mathrm{Al}, \mathrm{Si}$, dan Ca dengan kandungan kurang dari $10 \%$. Karakteristik bijih besi jenis magnetite ini yakni memiliki warna kehitam-hitaman, reduksi sukar, serta sifat magnet yang sangat kuat (Juharni, 2016). 


\section{Eri Widianto, Kardiman, Najmudin Fauji}

Karakterisasi Pasir Besi Alam Pantai Samudera Baru dan Pemanfaatannya sebagai Filler pada Sistem Penyaring Elektromagnetik

Perbedaan karakteristik fisik kandungan mineral pasir seperti $\mathrm{Fe}, \mathrm{Ti}, \mathrm{Mg}$, dan $\mathrm{Si}$ disebabkan oleh perbedaan lokasi endapan. Pasir besi sebagai salah satu bahan baku utama dalam industri baja dan industri alat berat lainnya di Indonesia, sehingga keberadaannya akhir-akhir ini memiliki peranan yang sangat penting di Indonesia dan bahkan ditingkat internasional (Ahmad, Triwikantoro, Pratapa, \& Darminto, 2009; Rahwanto, 2013).

$$
\text { Pengujian sistem penyaring }
$$
elektromagnetik menggunakan sampel air sungai yang ada di sekitar Karawang yang dianggap keruh dan tercemar limbah. Arus listrik yang diberikan pada pipa akan meningkatkan kuat medan magnet di dalam pipa solenoid, sesuai dengan Hukum Ampere tentang medan magnet, bahwa medan magnet berbanding lurus dengan kuat arus listrik. Solenoid yang terisi pasir besi memiliki kuat medan magnet yang lebih besar dibandingkan dengan solenoida yang belum diisi pasir besi. Hal ini disebabkan karena pasir besi yang berada dalam tabung solenoid telah terinduksi menjadi magnet atau dengan kata lain pasir besi telah termagnetisasi.

Pasir besi yang telah termagnetisasi memiliki medan magnet yang besar sehingga dapat menarik bahan yang mempunyai sifat kemagnetan. Semakin besar medan magnet pada pasir besi maka semakin besar daya tarik atau megnetisasinya terhadap bahan yang mempunyai sifat kemagnetan.

Tabel 4. Hasil pengujian kadar logam Fe

\begin{tabular}{cccc}
\hline $\begin{array}{c}\text { Kadar } \\
\text { awal } \\
(\mathrm{ppm})\end{array}$ & $\begin{array}{c}\text { Menit } \\
\text { ke- }\end{array}$ & $\begin{array}{c}\text { Kadar } \\
\text { Akhir } \\
(\mathrm{ppm})\end{array}$ & $\begin{array}{c}\text { Efektivitas } \\
(\%)\end{array}$ \\
\hline 1,2280 & 5 & 0,0510 & 95,8 \\
& 10 & $t t d$ & 100 \\
& 15 & 0,0813 & 93,3 \\
\hline
\end{tabular}

Ket. $t$ td $=$ tidak terdeteksi $/$ di bawah batas deteksi SSA ; $(-)=$ tidak diketahui, Batas deteksi $\mathrm{Fe}=0.02$ ppm

Hasil pengujian kadar logam $\mathrm{Fe}$ ditunjukkan pada Tabel 4. Secara umum hasil akhir pengujian menunjukkan penurunan kadar logam Fe yang memenuhi kadar maksimum yang masih diperbolehkan sesuai Peraturan Menteri Kesehatan Republik Indonesia Nomor 492/MENKES/PER/IV/2010 tentang syarat kualitas air minum yaitu untuk logam besi (Fe) sebesar $0,3 \mathrm{mg} / \mathrm{l}$.

Pada pengujian pada menit ke 10 diperoleh kadar akhir yang tidak terdeteksi alat, dengan kata lain semua logam besi terserap oleh sistem penyaring elektromagnetik. Pada menit ke 5 terdeteksi kadar Fe sebesar 0,051 ppm, hal ini disebabkan karena arus listrik yang cenderung tidak stabil sehingga pasir besi belum termagnetisasi dengan sempurna. Sedangkan pada menit ke 30, kadar Fe yang diperoleh justru lebih besar. Hal ini disebabkan karena sistem penyaring yang sudah cukup panas dan mengakibatkan pasir besi menjadi cepat jenuh, sehingga kemampuan menarik logam berkurang. Logam yang sudah tertarik pasir besi dapat lepas karena menurunnya kemagnetan pasir besi sebagai media penyaring yang dikarenakan adanya panas sehingga menaikkan suhu pada sistem penyaring elektromagnetik. Panas ini timbul akibat dari adanya arus listrik yang mengalir dalam solenoida. Namun secara keseluruhan efektivitas sistem penyaring mencapai di atas $90 \%$.

\section{KESIMPULAN}

Penelitian tentang analisis kandungan mineral pasir besi Pantai Samudera Baru Karawang telah dilakukan. Hasil karakterisasi pasir besi menggunakan SEM-EDX menunjukkan bahwa pasir besi dominan mengandung unsur Fe dan 0. Hasil penelitian menunjukkan bahwa pasir besi dapat digunakan sebagai filler pada sistem penyaring elektromagnetik untuk menurunkan kadar logam Fe pada air.

\section{UCAPAN TERIMA KASIH}

Peneliti mengucapkan terima kasih kepada LPPM UNSIKA yang telah memberikan dukungan financial berupa Hibah Internal DIPA UNSIKA dan semua pihak yang terlibat dalam penelitian ini.

\section{DAFTAR PUSTAKA}

Ahmad, T., Triwikantoro, T., Pratapa, S., \& Darminto, D. 2009. Sintesis Partikel Nano $\mathrm{Fe}_{3}-\mathrm{xMnxO}_{4}$ Berbasis Pasir Besi dan Karakterisasi Struktur serta Kemagnetannya. Jurnal NANOSAINS \& NANOTEKNOLOGI, 1(2), 67-73. Retrieved from

http://ijp.papsi.org/index.php/nano/arti cle/view/212

Fuad, A., Wulansari, R., \& Taufiq, A. 2010. Sintesa dan karakterisasi sifat struktur nano partikel $\mathrm{Fe} 3-\mathrm{x} \mathrm{MnxO}_{4}$ dengan metode kopresipasi, (227), 139-145.

Ghandoor, H. El, Zidan, H. M., Khalil, M. M. H., \& Ismail, M. I. M. 2012. Synthesis and Some Physical Properties of Magnetite $\left(\mathrm{Fe}_{3} \mathrm{O}_{4}\right)$ Nanoparticles, 7, 5734-5745. 


\section{Eri Widianto, Kardiman, Najmudin Fauji}

Karakterisasi Pasir Besi Alam Pantai Samudera Baru dan Pemanfaatannya sebagai Filler pada Sistem Penyaring Elektromagnetik

Husain, S., Suarso, E., \& Maddu, A. 2016. Karakterisasi Kandungan Bijih Besi Alam Sebagai Bahan Baku Magnetit Nanopartikel, 2016(September), 19-21.

Juharni. 2016. Karakteristik Pasir Besi di Pantai Marina Kabupaten Bantaeng.

Kartika, D. L., \& Pratapa, S. 2014. Sintesis Fe203 dari Pasir Besi dengan Metode Logam Terlarut Asam Klorida. Jurnal Sains Dan Seni Pomits, 3(2), 33-35.

Musthofa, F., Saputra, A., Puspitarini, Y., Rizaldi, P. D., Samsul, M., \& Firdaus, A. 2016. Sintesis Nanopartikel Magnet Zn- Ferrite $\left(\mathrm{ZnFe}_{2} \mathrm{O}_{4}\right)$ Berbahan Dasar Pasir Besi, 1(1), 1-5.

Rahwanto, A. 2013. Kajian Awal Karakteristik Mineral Magnetik Bijih Besi, 203-206.

Septityana, K. D., Priyono, P., Rochman, N. T., Yuswono, Rahman, T. P., Nugroho, D. W., ... Maulana, N. N. 2013. Sintesis dan karakterisasi pigmen hematit $\left(\mathrm{A}-\mathrm{Fe}_{2} \mathrm{O}_{3}\right)$ dari bijih besi alam melalui metode presipitasi. Youngster Physics Journal, 1(4), 95-100.

SLH Karawang. 2013. Status lingkungan hidup Kabupaten Karawang tahun 2013 Pemerintah Kabupaten Karawang.

Yulianto, A., Aji, M. P., \& Idayanti, N. 2010. Fabrikasi MnZn-ferit dari bahan alam pasir besi serta aplikasinya untuk core induktor, (April), 128-133.

Zain, A., \& Muliawan, A. 2016. Studi Penurunan Kadar Logam Besi (Fe) dan Logam Mangan (Mn) pada Lempung terhadap Perubahan Arus Listrik dalam Solenoida, 3(2), 72-76. 